\title{
Posttraining increases in REM sleep intensity implicate REM sleep in memory processing and provide a biological marker of learning potential
}

\author{
Carlyle T. Smith, ${ }^{1}$ Margaret R. Nixon, and Rebecca S. Nader \\ Department of Psychology, Trent University, Peterborough, Ontario K9J 7B8, Canada
}

\begin{abstract}
Posttraining rapid eye movement (REM) sleep has been reported to be important for efficient memory consolidation. The present results demonstrate increases in the intensity of REM sleep during the night of sleep following cognitive procedural/implicit task acquisition. These REM increases manifest as increases in total number of rapid eye movements (REMs) and REM densities, whereas the actual time spent in REM sleep did not change. Further, the participants with the higher intelligence (IQ) scores showed superior task acquisition scores as well as larger posttraining increases in number of REMs and REM density. No other sleep state changes were observed. None of the pretraining baseline measures of REM sleep were correlated with either measured IQ or task performance. Posttraining increases in REM sleep intensity implicate REM sleep mechanisms in further off-line memory processing, and provide a biological marker of learning potential.
\end{abstract}

There is now a substantial body of evidence from animal (Smith 1985, 1996; Datta 2000; Louie and Wilson 2001) and human (Smith 1995, 2001; Maquet et al. 2000; Stickgold et al. 2000; Laureys et al. 2001) studies to support the idea that further offline memory processing or consolidation occurs during postacquisition REM sleep. In humans, REM sleep is evidently important for the efficient memory consolidation of procedural/ implicit tasks (Smith 2001). In a recent review, all seven studies that imposed REM sleep deprivation after acquisition of procedural learning tasks reported subsequent memory deficits. As well, 14 of 16 studies which observed sleep following procedural task acquisition reported increases in time spent in REM sleep, percent REM sleep, or REM sleep intensity (Smith 2001).

The reported relationship between "native" or baseline amounts of REM sleep and learning potential, within or between species, has been inconsistent. REM sleep has been argued to be positively correlated with intelligence (Petre-Quadens and de Lee 1970; Pagel et al. 1973), negatively correlated with intelligence (Busby and Pivik 1983), and to have no relationship at all (Siegal 2001). However, it is likely that REM sleep has multiple functions (Rechtschaffen 1998), and thus it would be difficult to show such a singular relationship. It seems more likely that the posttraining REM sleep response to task acquisition, in terms of amount and/ or intensity, is a more useful indicator of learning potential. For example, it has been reported in rats (Smith and Wong 1991) that the magnitude of the posttraining REM sleep increase was dependent upon whether the animal was a "fast learner" or a "slow learner." Fast-learning animals showed marked increases in number of minutes of REM sleep, even following acquisition of simple tasks, whereas the slow-learning rats, although they did learn equally well, showed very small posttraining REM sleep increases. When the task became very difficult, only the rats that had exhibited large REM increases (fast learners) following the easy tasks were able to master the difficult task.

Differential learning ability and memory as they relate to posttraining REM sleep have never been closely examined in hu-

\section{'Corresponding author.}

E-mail csmith@trentu.ca; fax (705) 748-1580.

Article and publication are at http://www.learnmem.org/cgi/doi/10.1101/ Im.74904. mans. The present study was done to examine the posttraining sleep in humans following tasks known to require REM sleep for maximum memory consolidation efficiency (cognitive procedural/implicit tasks; Smith 2001). Thus the Mirror Trace task (Plihal and Born 1997) and the Tower of Hanoi (Smith 1995) were utilized. Groups of individuals at different levels of intelligence as measured by the Multidimensional Aptitude Battery (MAB-II; Jackson 1998) were exposed to these tasks.

It was predicted that all subjects would show behavioral improvements on the tasks following sleep. Based on previous reports (Smith 2001), it was further predicted that the posttraining REM sleep would show increases in either the number and density of REMs or time spent in REM sleep, or both. Subjects with higher scores on the MAB-II were expected to obtain higher acquisition and retest scores on the two tasks presented. Finally, it was predicted that subjects with higher acquisition and posttraining scores would show larger increases in REM sleep than those with lower scores. Baseline REM sleep (preacquisition) as well as all other sleep measures were predicted not to be correlated with any of the behavioral or intelligence measures.

\section{Results}

\section{The learning tasks}

Eighteen participants were trained on two tasks, the Mirror Trace task and the Tower of Hanoi, on the evening after completing their baseline night of sleep. A retest on these tasks took place one week later. These subjects also belonged to one of three ( $n=6 /$ group) subgroups of relatively high (HiQ), medium (MedQ), or low (LoQ) IQ. A nonlearning Control group $(n=6)$ spent the evening in the lab but were not exposed to the tasks.

For the Mirror Trace task, the time taken to finish the task dropped significantly from training to retest as shown by the combined groups factor $\left(F_{(1,15)}=91.05, P<0.0000\right)$. As well, the interaction effect was significant, showing a groups $\times$ task performance effect $\left(F_{(3,15)}=15.83, P<0.0003\right)$. The groups effect also reached significance $\left(F_{(1,2)}=7.41, P<0.006\right)$. NewmanKeuls post hoc tests revealed that the low IQ (LoQ) group took longer at training than the intermediate IQ (MedQ) group $(P<0.0002)$ and the high IQ $(\mathrm{HiQ})$ group $(P<0.0002)$. The 
MedQ and HiQ groups did not differ at training. None of the scores of these groups differed significantly at retest.

The ANOVA for the number of errors on this task showed a significant training effect as well. The combined groups repeated measure factor was $F_{(1,15)}=27.02, P<0.0001$. As with the time measure, the Newman-Keuls post hoc tests showed the errors at training to be highest for the LoQ group. Errors for this group were significantly higher than for the MedQ $(P<0.003)$ and the HiQ group $(P<0.004)$. The MedQ and HiQ groups did not differ from each other at training, and none of the groups differed on their retest scores. The training and retest measures for time and errors on the Mirror Trace task can be seen in Table 1 .

Analyses of the Tower of Hanoi data for time to complete the task showed a significant drop from training to retest $\left(F_{(1,15)}=84.14, P<0.0000\right)$ for combined groups. Post hoc tests revealed that at training, the LoQ group took longer than the HiQ group $(P<0.001)$. The MedQ group also took longer than the HiQ group to learn the task $(P<0.007)$. Groups did not differ at retest.

Analysis of the number of moves to complete this task showed a significant combined groups repeated-measures effect $\left(F_{(1,15)}=54.50, P<0.0000\right)$, once again revealing improvement after training. The groups $\times$ trials interaction was also significant $\left(F_{(2,15)}=3.89, P<0.05\right)$. The post hoc tests showed that the LoQ group required more moves at training than did the HiQ group $(P<0.001)$. The MedQ group also had more moves to completion than the HiQ group at acquisition $(P<0.009)$. Although the LoQ group also required more moves than the MedQ group at training, this effect was not statistically reliable. As with the other measures, the groups did not differ at retest. Because the HiQ group had the best acquisition scores on both tasks, the amount of improvement was greatest for the LoQ, less for the MedQ, and least for the HiQ group. The training and retest scores for both measures on the Tower of Hanoi can be seen in Table 2 .

\section{The sleep data}

The most obvious result was the increase in number of REMs from baseline to posttraining sleep night. An ANOVA of all the subjects who learned the task (LoQ, MedQ, and HiQ groups combined or Combined Trained ) versus the nonlearning Controls in a mixed model between-within repeated measures ANOVA revealed that there was a significant combined trained groups effect $\left(F_{(1,20)}=14.16, P<0.002\right)$. Further, there was a significant groups $\times$ nights interaction $\left(F_{(3,20)}=3.25, P<0.05\right)$. A post hoc Newman-Keuls revealed that the various IQ and Control groups did not differ on baseline night. However, subjects in all three trained groups showed a significant increase in number of REMs on posttraining sleep night compared to the nonlearning controls $(P<0.0003$ for the HiQ group, $P<0.0006$ for MedQ group, and $P<0.02$ for the LoQ group). Only the HiQ subjects showed significant increases from their own baseline pretraining values as well (Newman-Keuls: $P<0.007)$. Results can be seen in Figure 1.

A similar ANOVA of REM density (total number of REMs/ total min of REM sleep) again revealed a combined trained groups effect from baseline to posttraining night $\left(F_{(1,20)}=6.61\right.$, $P<0.02)$. A post hoc Newman-Keuls revealed that the HiQ group had a significantly higher density value than the Controls on posttraining night $(P<0.01)$ as did the MedQ group $(P<0.04)$. The density increase in the LoQ group, although it increased, did not reach significance compared to Controls. None of the groups differed on baseline night.

To determine whether any one particular REM period might exhibit a greater number of REMs or higher REM density than the others, we examined the four individual REM periods separately. The two groups (Combined Trained vs. Control) did not differ on baseline night. However, on posttraining night, the ANOVA comparing these two groups, while keeping the REM periods separate, showed the Combined Trained group to have a larger number of REMs than the Controls $\left(F_{(1,22)}=8.96, P<0.007\right)$. Both groups also showed an increase in number of REMs as the night progressed $\left(F_{(3,66)}=3.33, P<0.02\right)$. Post hoc analyses of the separate REM periods did not reveal any individual REM period differences between Combined Trained and corresponding Control subjects. However, as can be seen from Figure 2, REM periods 2,3 , and 4 appeared to contribute substantially to the overall result. The same general pattern was observed using the REM density measure, although the results only approached significance.

The number of minutes of REM sleep and the \%REM sleep measures showed no significant differences between groups either at baseline or on posttraining night. Further, no other sleep measures, including Stage 1, Stage 2, Stage 3/4 (stages 3 and 4 were combined to give an estimate of amount of deep slow wave sleep [SWS]), or Total sleep were found to differ between groups on either night; all sleep values can be seen in Table 3 .

\section{Correlations}

Correlations were performed between the MAB-II Full Scale IQ score of each subject and the performance scores of the two tasks. This MAB score was significantly negatively correlated with the amount of time required to learn the Mirror Trace $(r=-0.63$, $P<0.05)$ and the Tower of Hanoi $(r=-0.50, P<0.05)$ tasks. The same effect was observed for acquisition errors on the Mirror Trace $(r=-0.52, P<0.05)$ and acquisition number of moves required on the Tower of Hanoi $(r=-0.57, P<0.05)$. There was also a correlation between Mirror Trace improvement scores on the time $(r=-0.72, P<0.05)$ and error $(r=-0.56, P<0.05)$ measures versus Full Scale IQ. The correlations for the difference measures for the Tower of Hanoi task did not reach significance, although they were substantial (time, $r=-0.43$, and moves, $r=-0.45)$. There were no significant correlations between the MAB scores and any of the sleep measures on either baseline or posttraining night.

A number of correlations were performed to examine the relationship between the sleep states and performance. Because the only measures to change significantly were the number of REMs and REM density measures, correlations were performed on these variables and the training versus retest score differences.

The overall mean density of REMs on posttraining night was

Table 1. Mean mirror trace acquisition and retest data

\begin{tabular}{lcccccc}
\hline & $\begin{array}{c}\text { LoQ } \\
\text { training }\end{array}$ & $\begin{array}{c}\text { LoQ } \\
\text { re-test }\end{array}$ & $\begin{array}{c}\text { MedQ } \\
\text { training }\end{array}$ & $\begin{array}{c}\text { MedQ } \\
\text { re-test }\end{array}$ & $\begin{array}{c}\text { HiQ } \\
\text { training }\end{array}$ & $\begin{array}{c}\text { HiQ } \\
\text { re-test }\end{array}$ \\
\hline Mean time (sec) & $250.4(21.0)$ & $84.6(3.3)$ & $121.5(21.4)$ & $71.8(12.5)$ & $146.2(17.5)$ & $90.3(10.1)$ \\
Mean \# of errors & $68.4(16.5)$ & $21.83(4.3)$ & $36.0(8.9)$ & $18.0(3.5)$ & $32.6(7.0)$ & $16.0(3.3)$ \\
\hline
\end{tabular}

Data include ( \pm S.E.M.) 
Table 2. Tower of hanoi acquisition and retest data

\begin{tabular}{lcccccc}
\hline & $\begin{array}{c}\text { LoQ } \\
\text { training }\end{array}$ & $\begin{array}{c}\text { LoQ } \\
\text { re-test }\end{array}$ & $\begin{array}{c}\text { MedQ } \\
\text { training }\end{array}$ & $\begin{array}{c}\text { MedQ } \\
\text { re-test }\end{array}$ & $\begin{array}{c}\text { HiQ } \\
\text { training }\end{array}$ & $\begin{array}{c}\text { HiQ } \\
\text { re-test }\end{array}$ \\
\hline Mean time (sec) & $598.5(75.0)$ & $260.3(59.5)$ & $521.7(73.0)$ & $196.3(38.2)$ & $355.9(52.1)$ & $188.0(20.5)$ \\
Mean \# of moves & $222.2(26.8)$ & $135.4(20.0)$ & $193.8(10.7)$ & $104.3(8.0)$ & $144.3(9.2)$ & $111.8(13.8)$ \\
\hline
\end{tabular}

Data include ( \pm S.E.M.)

significantly correlated with improvement (moves to solution) on the Tower of Hanoi task $(r=-0.56, P<0.05)$. Similar effects were seen when correlating improvement (time) with the mean densities of the first two REM periods $(1+2)$ alone $(r=-0.48$, $P<0.05)$ and the last two REM periods $(3+4)$ alone $(r=-0.50$, $P<0.05)$. When individual REM periods were correlated with improvement (time), only REM period 2 was found to be significantly correlated $(r=-0.62, P<0.05)$. For the Mirror Trace task, overall improvement (time) was significantly correlated with the number of REMs in REM period 4 on posttraining night $(r=-0.53, P<0.05)$. All correlations can be seen in Table 4 .

\section{Discussion}

REM sleep is characterized by a complex organized set of phenomena, including desynchronized EEG (7-10 Hz in humans), atonia of the major muscle groups, rapid eye movements, and marked fluctuations of the autonomic nervous system. In animals, there is a pronounced $\theta$ rhythm in the hippocampus, as well as field potentials in the pons, lateral geniculate, and visual cortex called ponto-geniculo-occipital (PGO) waves. Common brain stem mechanisms are involved in the activation of the various components of REM sleep, including rapid eye movements (Datta and Hobson 1994; Datta 1995). Thus, it seems reasonable that the number of REMs and REM density measures are good indicators of REM sleep intensity.

The present findings supported our hypothesis that REM sleep increases would follow acquisition of the cognitive procedural tasks. Both the number and density of REMs showed higher values following acquisition, whereas the time in REM sleep and $\%$ REM sleep did not change from baseline to posttest. These results are similar to our own previous findings (Smith and Lapp

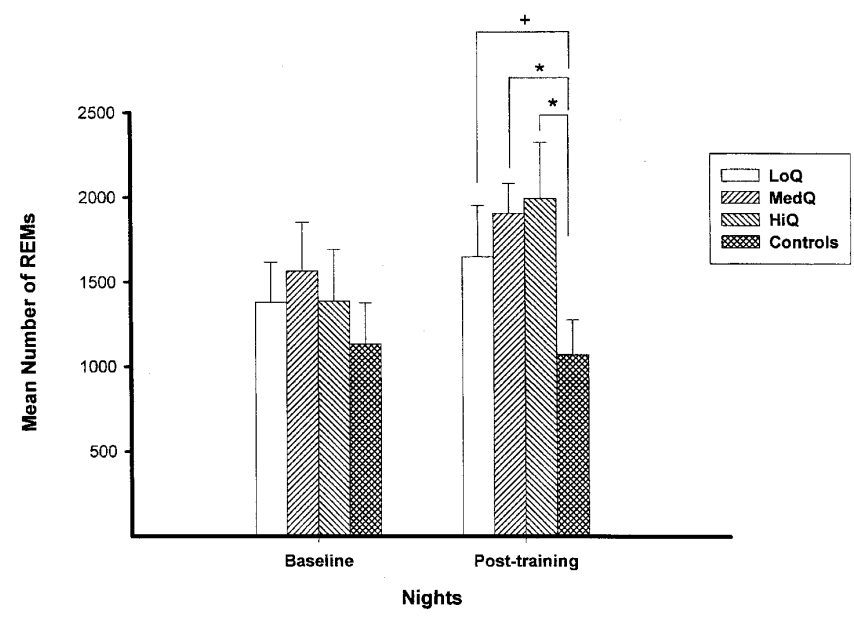

Figure 1. Total number of rapid eye movements (REMs) on baseline night and the night after training (+S.E.M.) for the LoQ, MedQ, HiQ, and nontrained Control groups. All trained groups differed from the control group on posttraining night. * indicates $P<0.006,+$ indicates $P<0.02$. The HiQ group also differed from its own baseline value $(P<0.007)$.
1991). A number of other earlier human studies reported increases in REMs/REM densities (Verschoor and Holdstock 1984; Mandai et al. 1989; DeKoninck and Prevost 1991), whereas several (Fanjaud et al. 1982; Scrima 1982; DeKoninck et al. 1989; Buchegger et al. 1991) reported increases in REM sleep time alone. One study reported a high correlation between performance level and time spent in REM in the last quarter of the night (Stickgold et al. 2000). The reasons for these differing posttraining changes in REM sleep are not clear (Smith 2001), and no systematic examination of such variables as type of learning task has yet been done. In rodents, the great majority of studies have reported increases in time spent in REM sleep following successful task acquisition (for review, see Smith 1985, 1996). Although actual eye movement recording has never been done in rodents, one study did examine REMs activity (Smith and Lapp 1986). In this study both number of minutes spent in REM sleep and number of REMs increased, but there was no change in REM density following acquisition of a shuttle avoidance task. More recently, Datta (2000) trained rats in a shuttle avoidance task and observed a $25 \%$ increase in posttraining REM sleep as well as an increase in density of the P wave (PGO equivalent in the rat), an even better measure of phasic REM activity emanating from the brainstem. The level of acquisition was highly correlated with the density of P-wave activity, and P-wave density increases were proportional to the improvement in task performance. Thus in rats, as in humans, time in REM, number of REMs, and REM density have all been reported to increase following successful task acquisition.

There was no correlation in the present study between REM sleep parameters and IQ values. As mentioned in the introduction, this should not be surprising. REM sleep has been argued to be involved in a number of basic activities that have very little to do with intelligence, including emotional adaptation, compensation for non-REM (NREM) sleep activities, endogenous stimulation of the brain, cerebral maturation, binocular coordination, and rehearsal of genetically programmed behaviors (Rechtschaffen 1998). There are undoubtedly other functions to be discovered. Thus, although REM sleep might also be involved with learning and memory consolidation, it would be difficult to detect this relationship using the standard IQ test, which itself measures a range of learning potentials.

In previous work (Smith and Wong 1991), we observed that although all rats learned the simple tasks to the same level, the animals with only small increases in posttraining REM sleep were unable to learn the most difficult task. On the other hand, those rats with very large REM sleep changes following even the simpler tasks were able to learn the difficult task as well. Thus, we were able to divide the animals into two groups, a fastlearning (more intelligent) group and a slow-learning (less intelligent) group. The results of that study indicated that the rats showing a large REM response to easy tasks were those also capable of learning very difficult material. Further, the amount of REM sleep above normal baseline levels climbed even higher following successful acquisition of the very difficult task. The results of the present study showed a similar pattern, in that individuals with the highest IQ scores also responded to the two 
Table 3. Sleep measures for each of the groups including the LoQ, MedQ, HiQ, and nontrained control groups

\begin{tabular}{|c|c|c|c|c|c|c|c|c|}
\hline $\begin{array}{l}\text { Sleep } \\
\text { measure }\end{array}$ & $\begin{array}{c}\text { LoQ } \\
\text { baseline } \\
\text { night }\end{array}$ & $\begin{array}{l}\text { LoQ } \\
\text { post-train } \\
\text { night }\end{array}$ & $\begin{array}{l}\text { MedQ } \\
\text { baseline } \\
\text { night }\end{array}$ & $\begin{array}{l}\text { MedQ } \\
\text { post-train } \\
\text { night }\end{array}$ & $\begin{array}{c}\text { HiQ } \\
\text { baseline } \\
\text { night }\end{array}$ & $\begin{array}{c}\text { HiQ } \\
\text { post-train } \\
\text { night }\end{array}$ & $\begin{array}{l}\text { Controls } \\
\text { baseline } \\
\text { night }\end{array}$ & $\begin{array}{l}\text { Controls } \\
\text { post-train } \\
\text { night }\end{array}$ \\
\hline $\begin{array}{l}\text { Awake after } \\
\text { sleep onset }\end{array}$ & $\begin{array}{c}3.9 \\
(1.7)\end{array}$ & $\begin{array}{c}1.7 \\
(1.3)\end{array}$ & $\begin{array}{l}13.0 \\
(1.7)\end{array}$ & $\begin{array}{c}4.3 \\
(2.1)\end{array}$ & $\begin{array}{l}10.7 \\
(6.4)\end{array}$ & $\begin{array}{c}4.3 \\
(1.9)\end{array}$ & $\begin{array}{c}4.3 \\
(2.2)\end{array}$ & $\begin{array}{c}2.4 \\
(8.3)\end{array}$ \\
\hline Stage 1 & $\begin{array}{c}9.4 \\
(1.8)\end{array}$ & $\begin{array}{l}10.2 \\
(1.7)\end{array}$ & $\begin{array}{l}12.2 \\
(3.6)\end{array}$ & $\begin{array}{l}8.9 \\
(1.6)\end{array}$ & $\begin{array}{l}12.8 \\
(4.9)\end{array}$ & $\begin{array}{l}16.3 \\
(3.7)\end{array}$ & $\begin{array}{c}8.0 \\
(2.6)\end{array}$ & $\begin{array}{l}11.3 \\
(2.0)\end{array}$ \\
\hline Stage 2 & $\begin{array}{l}274.0 \\
(11.4)\end{array}$ & $\begin{array}{l}276.5 \\
(10.1)\end{array}$ & $\begin{array}{l}278.8 \\
(12.9)\end{array}$ & $\begin{array}{l}290.2 \\
(26.4)\end{array}$ & $\begin{array}{l}290.2 \\
(19.0)\end{array}$ & $\begin{array}{l}277.3 \\
(13.2)\end{array}$ & $\begin{array}{l}280.3 \\
(15.4)\end{array}$ & $\begin{array}{l}272.8 \\
(14.9)\end{array}$ \\
\hline Stage $3 / 4$ & $\begin{array}{c}44.6 \\
(11.2)\end{array}$ & $\begin{array}{l}47.0 \\
(9.1)\end{array}$ & $\begin{array}{c}48.3 \\
(13.2)\end{array}$ & $\begin{array}{l}48.3 \\
(9.4)\end{array}$ & $\begin{array}{c}44.4 \\
(15.5)\end{array}$ & $\begin{array}{l}39.1 \\
(10.0)\end{array}$ & $\begin{array}{l}35.3 \\
(9.2)\end{array}$ & $\begin{array}{l}35.9 \\
(7.1)\end{array}$ \\
\hline Stage REM & $\begin{array}{l}113.0 \\
(10.0)\end{array}$ & $\begin{array}{c}114.6 \\
(6.7)\end{array}$ & $\begin{array}{l}114.1 \\
(12.0)\end{array}$ & $\begin{array}{l}114.8 \\
(10.2)\end{array}$ & $\begin{array}{l}98.0 \\
(11.2)\end{array}$ & $\begin{array}{c}113.7 \\
(8.8)\end{array}$ & $\begin{array}{c}104.7 \\
(7.9)\end{array}$ & $\begin{array}{c}103.1 \\
(9.4)\end{array}$ \\
\hline Total sleep & $\begin{array}{l}444.6 \\
(18.0)\end{array}$ & $\begin{array}{l}453.6 \\
(15.5)\end{array}$ & $\begin{array}{l}455.7 \\
(16.1)\end{array}$ & $\begin{array}{l}464.3 \\
(16.8)\end{array}$ & $\begin{array}{l}448.7 \\
(11.5)\end{array}$ & $\begin{array}{l}452.4 \\
(14.2)\end{array}$ & $\begin{array}{l}442.2 \\
(19.1)\end{array}$ & $\begin{array}{l}451.9 \\
(12.1)\end{array}$ \\
\hline \%REM & $\begin{array}{c}25.4 \\
(2.1)\end{array}$ & $\begin{array}{c}25.2 \\
(1.1)\end{array}$ & $\begin{array}{l}24.9 \\
(2.2)\end{array}$ & $\begin{array}{l}25.0 \\
(2.5)\end{array}$ & $\begin{array}{l}21.7 \\
(2.1)\end{array}$ & $\begin{array}{l}25.4 \\
(1.8)\end{array}$ & $\begin{array}{l}23.9 \\
(1.9)\end{array}$ & $\begin{array}{l}23.0 \\
(2.4)\end{array}$ \\
\hline Total REMs & $\begin{array}{l}1379.0 \\
(234.9)\end{array}$ & $\begin{array}{l}1646.7^{b} \\
(304.2)\end{array}$ & $\begin{array}{l}1562.7 \\
(287.6)\end{array}$ & $\begin{array}{l}1903.5^{a} \\
(177.5)\end{array}$ & $\begin{array}{l}1386.0 \\
(303.9)\end{array}$ & $\begin{array}{l}1993.3^{a} \\
(329.8)\end{array}$ & $\begin{array}{l}1133.0 \\
(244.4)\end{array}$ & $\begin{array}{l}1070.0 \\
(205.7)\end{array}$ \\
\hline REM density & $\begin{array}{c}12.2 \\
(1.5)\end{array}$ & $\begin{array}{l}14.1 \\
(3.1)\end{array}$ & $\begin{array}{c}13.5 \\
(1.8)\end{array}$ & $\begin{array}{c}16.8^{\mathrm{b}} \\
(1.0)\end{array}$ & $\begin{array}{l}14.7 \\
(3.5)\end{array}$ & $\begin{array}{l}18.1^{\mathrm{a}} \\
(3.5)\end{array}$ & $\begin{array}{l}10.7 \\
(1.7)\end{array}$ & $\begin{array}{l}10.8 \\
(2.0)\end{array}$ \\
\hline
\end{tabular}

andicates $P<0.007$ compared to corresponding Control posttraining night value.

bIndicates $P<0.020$ compared to corresponding Control posttraining night value.

(Newmann-Keuls post hoc tests).

tasks with the largest increase in number of REMs. Unlike the animal study, the subjects in all groups were able to learn the two tasks. There was no task of extreme difficulty that was too hard for the LoQ or MedQ groups to provide results to parallel the animal findings.

We did not observe a significant difference on task performance between groups at posttraining retest, although it might have been expected that the groups would show differential final scores with the HiQ group being the best and the LoQ group being the worst. However, the scores of the three trained groups were still slightly different from each other at this point, and the LoQ group still had more errors on the Mirror Trace task than the MedQ group, which in turn had more errors than the HiQ group. Similarly, the LoQ group had the largest number of moves on the Tower of Hanoi compared to the MedQ and HiQ groups (the MedQ was actually marginally higher than the HiQ group), although none of the differences were statistically reliable. It should be noted that the IQ groups were arbitrarily chosen from

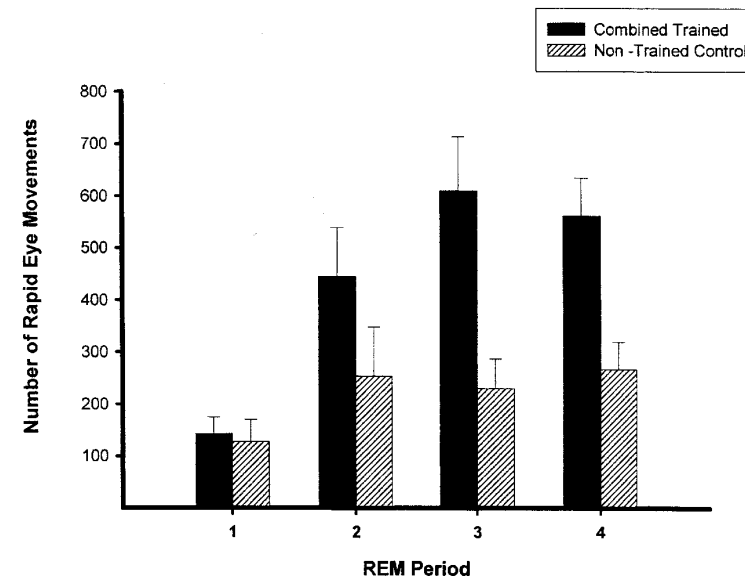

Figure 2. Number of rapid eye movements (REMs) on posttraining night for the Combined Trained group vs. the nontrained Control group. The Combined Trained group had significantly more REMs overall $(P<0.007)$. our academic setting, and that all groups were at least slightly above average in measured IQ. Thus, acquisition of our tasks was within reach of all participants.

One interesting result was the finding that although the increases in REMs sleep parameters were smaller, for example, in the LoQ compared to the HiQ group, the benefit of the night of sleep appeared greater for the LoQ group, even though final scores were still slightly higher for the HiQ group. These results add a new dimension to the sleep-learning literature, and many questions remain. It seems reasonable to assume that the REM sleep state provides an efficient environment for the further processing of recently learned material. During REM sleep, the individual subject apparently engages in specialized posttraining activity, including neuronal replay of recently learned material (Maquet et al. 2000; Louie and Wilson 2001). Although we can only speculate, it is possible that the lower-IQ groups engaged in more neuronal reactivation or reprocessing during the posttraining REM sleep than the HiQ group. This does not rule out the possibility that the REM sleep system of the HiQ group was more efficient, and overnight improvement obviously occurred in this group as well.

In an attempt to explain these results, we propose a model which suggests that the posttraining REM response following task acquisition is partly genetically determined and partly a response to the task itself. This would mean that for any given task, the REM response of the HiQ group would be larger than for lower-IQ groups, but that it would also be partly responsive to task difficulty. Thus more intelligent individuals would exhibit a larger increase in number of REMs to a modestly difficult task and an even higher number of REMs for a more difficult task. Lessintelligent individuals would show a smaller REM response to the modestly difficult task, and a proportionally larger increase to the more difficult task. At the point where any of the individuals were unable to learn a task, there would be expected to be no REM increases, a phenomenon that has been observed in a number of animal studies (Smith 1985, 1996).

Previous studies have suggested the possibility that single REM periods (REM windows) might be particularly important for specific tasks (Smith and Lapp 1991; Stickgold et al. 2000). In the present study, no single REM period appeared to have more REMs 
Table 4. Correlations

\begin{tabular}{lcc}
\hline Correlation pair & $\begin{array}{c}\text { Correlation } \\
\text { value }\end{array}$ & $\begin{array}{c}\text { Significance } \\
\text { level }\end{array}$ \\
\hline MAB full score vs. MT acquisition errors & -.52 & .05 \\
MAB full score vs. MT acquisition time & -.63 & .57 \\
MAB full score vs. T of H acquisition moves & -.57 \\
MAB full score vs. T of H acquisition time & -.50 & -.56 \\
MAB full score vs. MT improvement score (errors) & -.72 & .05 \\
MAB full score vs. MT improvement score (time) & -.45 & -.43 \\
MAB full score vs. T of H improvement score (moves) & -.56 & .05 \\
MAB full score vs. T of H improvement score (time) & -.48 \\
Mean density of REMs (all REM periods) on posttraining night vs. T of H improvement (moves) & -.05 \\
Mean density of REMs (REM periods 1 + 2) on posttraining night vs. mean T of H improvement (time) & .05 \\
Mean density of REMs (REM periods 3 + 4) on posttraining night vs. mean T of H improvement (time) & .05 \\
Mean density of REMs (REM period 2) on posttraining night vs. mean T of H improvement (time) & .05 \\
Mean number of REMs (period 4) on posttraining night vs. mean improvement on MT (time) & -.62 \\
\hline
\end{tabular}

MAB, Multidimensional Aptitude Battery; T of H, Tower of Hanoi Task; MT, Mirror Trace Task; NS, not significant.

All correlations are Pearson correlation coefficients.

or higher REM density, although the last three REM periods all appeared to have partially contributed to the process. The fact that two different tasks were used makes the finding of a REM window (Smith and Lapp 1991; Stickgold et al. 2000) more difficult. However, the correlations do hint that separate REM periods (REM windows) do exist for the two tasks. Whereas the improvement (time) to do the Tower of Hanoi was most highly correlated with the REM density in REM period 2, improvement (time) on the Mirror Trace task was most highly correlated with the number of REMs in REM period 4.

In summary, our findings indicate that there is a significant relationship between REM sleep intensity and memory consolidation. Individuals assessed (MAB-II) as having the highest learning potential also had the best acquisition scores and exhibited the most dramatic posttraining total REMs/REM density increases. Further, the improvement in task performance was significantly correlated with both the number of posttraining REMs and REM densities. These results suggest that the magnitude of the posttraining REM sleep intensity increases might well provide a biological marker of learning potential.

\section{Materials and Methods}

Participants were eight male and 16 female $(n=24)$ undergraduate college students, equally distributed in four groups and screened for normal sleep habits using the Trent University Sleep Questionnaire. All subjects were between the ages of 19 and 25 years. Screened subjects were asked to fill out the Multidimensional Aptitude Battery (MAB-II). The MAB-II is a test of general intelligence developed to efficiently test both verbal and performance potential. The verbal and performance scales each have five subscales. The full-scale measure is composed of the assessment of a number of different abilities of the individual. The test provides an IQ score that shows a very high (0.91) correlation with the more widely used Wechsler Adult Intelligence Scale (WAIS), and based on the final full score of this test, individuals were placed in one of four groups $(n=6 /$ group), HiQ $($ mean $=125.8, \mathrm{SD}=2.31)$, MedQ $($ mean $=114.7, \mathrm{SD}=2.73)$, LoQ $($ mean $=102.5, S D=3.01)$, or Control $($ mean $=108.3$, $\mathrm{SD}=13.7)$. No individual IQ score from one test group overlapped with that of individuals in any other test group, whereas the Control group was composed of individuals with scores at all IQ levels. The study was approved by the Trent University Ethics committee, and written, informed consent was obtained from all subjects.

The learning tasks chosen were assessed to be of the cognitive procedural type and known to involve REM sleep during postacquisition memory processing. Thus the Mirror Trace task (Plihal and Born 1997) and the Tower of Hanoi (Smith 1995) were utilized. Although neither task could be considered a "pure" procedural task, both undoubtedly have a large procedural component. Chosen subjects in all groups were asked to stay over in the sleep lab for three consecutive nights. EEG, eye movements (EOG) from both eyes, and EMG (from chin muscles) were recorded using a paperless polygraph system. Analyses of the REM periods was restricted to the first four observed, because only three individuals had five REM periods, whereas all subjects had at least four REM periods. Electrode placement and sleep staging were done using the standard method (Rechtschaffen and Kales 1968). The first night (acclimatization) of recording was not used. EOG deflections of $7 \mu \mathrm{V}$ or larger in at least one eye were counted as eye movements. The sleep data on the second night were the baseline measures of sleep for each subject. On the third evening, the subjects in the test groups were exposed to the two training tasks (presented in random order) prior to the final posttraining night of recording. Control subjects spent the third evening in the lab and were allowed to watch movies or read, but were not allowed to study. Subjects in the trained groups were asked to come back to the lab $1 \mathrm{wk}$ later for retest on the two tasks, and all were retested at the same time as they were trained in order to minimize any circadian effects.

\section{Acknowledgments}

This work was supported in part by the Natural Sciences and Engineering Research Council of Canada and the Canadian Institutes of Health Research.

\section{References}

Buchegger, J., Fritsch, R., Meier-Koll, A., and Riehle, H. 1991. Does trampolining and anaerobic physical fitness affect sleep? Percept. Mot. Skills 73: 243-252.

Busby, K. and Pivik, R.T. 1983. Sleep patterns in children of superior intelligence. J. Child Psychol. Psychiat. 24: 587-600.

Datta, S. 1995. Neuronal activity in the peribrachial area: Relationship to behavioral state control. Neurosci. Biobehav. Rev. 19: 67-84.

. 2000. Avoidance task training potentiates phasic pontine-wave density in the rat: A mechanism for sleep-dependent plasticity. $J$. Neurosci. 20: 8607-8613.

Datta, S. and Hobson, J.A. 1994. Neuronal activity in the caudolateral peribrachial pons: Relationship to PGO waves and rapid eye movements. J. Neurophysiol. 71: 95-109.

DeKoninck, J. and Prevost, F. 1991. Le sommeil paradoxal et le traitment de l'information: Une exploration par l'inversion du champ visuel. Can. J. Psychol. 45: 125-139.

DeKoninck, J., Lorrain, D., Christ, G., Proulx, G., and Coulombe, D. 1989. Intensive language learning and increases in rapid eye movement sleep: Evidence of a performance factor. Internat. $J$. Psychophysiol. 8: 43-47.

Fanjaud, G., Calvet, U., De Feneyrols, R.A., Barrere, M., Bes, A., and Arbus, L. 1982. Role du sommeil paradoxal dans l'apprentissage chez l'homme. Rev. E.E.G. Neurophysiol. 12: 337-343. 
Jackson, D.N. 1998. Multidimensional Aptitude Battery-II. Research Psychologists Press Inc., London, Ontario.

Laureys, S., Peigneux, P., Phillips, C., Fuchs, S., Degueldre, C., Aerts, J., Del Fiore, G., Petiau, C., Luxen, A., van der Linden, M., et al. 2001. Experience-dependent changes in cerebral functional connectivity during rapid eye movement sleep. Neurosci. 105: 521-525.

Louie, K. and Wilson, M.A. 2001. Temporally structured replay of awake hippocampal ensemble activity during rapid eye movement sleep. Neuron. 29: 145-156.

Mandai, O., Guerrien, A., Sockeel, P., Dujardin, K., and Leconte, P. 1989. REM sleep modifications following a morse code learning session in humans. Physiol. Behav. 46: 639-642.

Maquet, P., Laureys, S., Peigneux, P., Fuchs, S., Petiau, C., Phillips, C., Aerts, J., Del Fiore, G., Degueldre, C., Meulemans, T., et al. 2000. Experience-dependent changes in cerebral activation during human REM sleep. Nat. Neurosci. 3: 831-836.

Pagel, J., Pegram, V., Vaughn, S., Donaldson, P., and Bridgers, W. 1973. The relationship of REM sleep with learning and memory in mice. Behav. Biol. 9: 383-388.

Petre-Quadens, O. and de Lee, C. 1970. Eye-movements during sleep: A common criterion of learning capacities and endocrine activity. Dev. Med. Child Neurol. 12: 730-740.

Plihal, W. and Born, J. 1997. Effects of early and late nocturnal sleep on declarative and procedural memory. J. Cog. Neurosci. 9: 534-547.

Rechtschaffen, A. 1998. Current perspectives on the function of sleep. Perspect. Biol. Med. 41: 359-390.

Rechtschaffen, A. and Kales, A. 1968. A manual of standardized terminology, techniques and scoring system for sleep scoring stages of human subjects. U.S. Department of Health, Education and Welfare, Public Health Services, Bethesda, Maryland, USA.
Scrima, L. 1982. Isolated REM sleep facilitates recall of complex associative information. Psychophysiol. 19: 252-258.

Siegal, J.M. 2001. The REM sleep-memory consolidation hypothesis. Science 294: 1058-1063.

Smith, C.T. 1985. Sleep states and learning: A review of the animal literature. Neurosci. Biobehav. Rev. 9: 157-168.

1995. Sleep states and memory processes. Behav. Brain Res. 69: $137-145$.

1996. Sleep states, memory processes and synaptic plasticity. Behav. Brain Res. 78: 49-56.

2001. Sleep states and memory processes in humans: Procedural vs. declarative memory systems. Sleep Med. Rev. 5: 491-506.

Smith, C. and Lapp, L. 1986. Prolonged increases in both PS and number of REMs following a shuttle avoidance task. Physiol. Behav. 36: 1053-1057.

1991. Increases in number of REMs and REM density in humans following an intensive learning period. Sleep 14: 325-330.

Smith, C. and Wong, P.T.P. 1991. Paradoxical sleep increases predict successful learning in a complex operant task. Behav. Neurosci. 105: $282-288$.

Stickgold, R., Whidbee, D., Schirmer, B., Patel, V., and Hobson, J.A. 2000. Visual discrimination task improvement: A multistep process occurring during sleep. J. Cog. Neurosci. 12: 246-254.

Verschoor, G.J. and Holdstock, T.L. 1984. REM bursts and REM sleep following visual and auditory learning. South Afr. J. Psych. 14: $69-74$.

Received January 26, 2004; accepted in revised form June 1, 2004. 


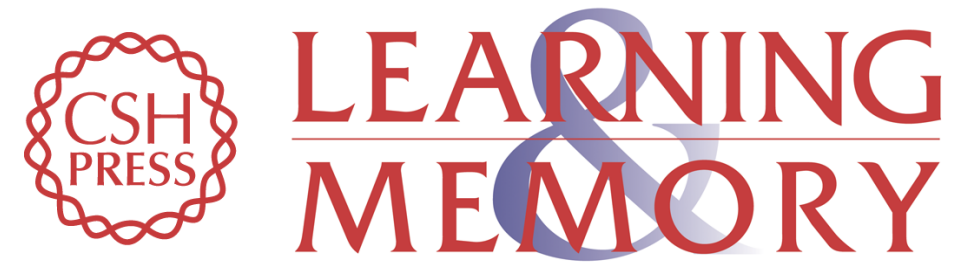

\section{Posttraining increases in REM sleep intensity implicate REM sleep in memory processing and provide a biological marker of learning potential}

Carlyle T. Smith, Margaret R. Nixon and Rebecca S. Nader

Learn. Mem. 2004, 11:

Access the most recent version at doi:10.1101//m.74904

References This article cites 25 articles, 2 of which can be accessed free at: http://learnmem.cshlp.org/content/11/6/714.full.html\#ref-list-1

License

Email Alerting

Receive free email alerts when new articles cite this article - sign up in the box at the Service top right corner of the article or click here. 